UCRL-JC-124629

PREPRINT

\title{
Near-Field Thermal-Hydrological Behavior for Alternative Repository Designs at Yucca Mountain
}

\author{
Thomas A. Buscheck \\ John J. Nitao \\ Lawrence D. Ramspott
}

This paper was prepared for submittal to the

Materials Research Society Fall Meeting

December 2-6, 1996

Boston, MA

December 1996

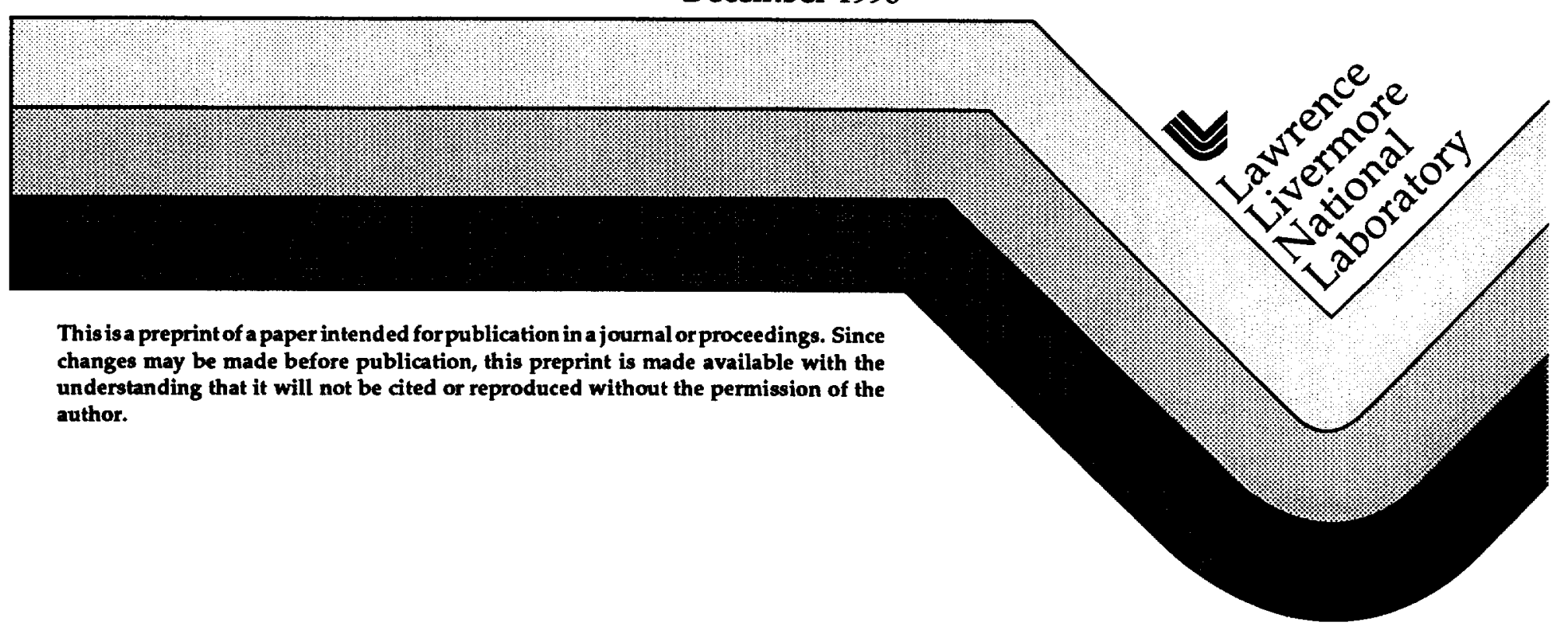




\section{DISCLAIMER}

This document was prepared as an account of work sponsored by an agency of the United States Government. Neither the United States Government nor the University of California nor any of their employees, makes any warranty, express or implied, or assumes any legal liability or responsibility for the accuracy, completeness, or usefulness of any information, apparatus, product, or process disclosed, or represents that its use would not infringe privately owned rights. Reference herein to any specific commercial products, process, or service by trade name, trademark, manufacturer, or otherwise, does not necessarily constitute or imply its endorsement, recommendation, or favoring by the United States Government or the University of California. The views and opinions of authors expressed herein do not necessarily state or reflect those of the United States Government or the University of California, and shall not be used for advertising or product endorsement purposes. 


\section{NEAR-FIELD THERMAL-HYDROLOGICAL BEHAVIOR FOR ALTERNATIVE REPOSITORY DESIGNS AT YUCCA MOUNTAIN}

THOMAS A. BUSCHECK, * JOHN J. NITAO,* AND LAWRENCE D. RAMSPOTT**

*Geological Sciences and Environmental Technologies Division, LLNL, ${ }^{* *}$ TRW (all at Lawrence Livermore National Laboratory, L-206, P.O. Box 808, Livermore, CA 94551)

\section{ABSTRACT}

Three-dimensional calculations that explicitly represent a realistic mixture of waste packages (WPs) are used to analyze decay-heat-driven thermal-hydrological behavior around emplacement drifts in a potential high-level waste facility at Yucca Mountain. Calculations, using the NUFT code, compare two fundamentally different ways that WPs can be arranged in the repository, with a focus on temperature, relative humidity, and liquid-phase flux on WPs. These quantities strongly affect WP integrity and the mobilization and release of radionuclides from WPs. Point-load spacing, which places the WPs roughly equidistant from each other, thermally isolates WPs from each other, causing large variability in temperature, relative humidity, and liquid-phase flux along the drifts. Line-load spacing, which places WPs nearly end to end in widely spaced drifts, results in more locally intensive and uniform heating along the drifts, causing hotter, drier, and more uniform conditions. A larger and more persistent reduction in relative humidity on WPs occurs if the drifts are backfilled with a low-thermal-conductivity granular material with hydrologic properties that minimize moisture wicking.

\section{INTRODUCTION}

The U.S. Department of Energy is investigating the feasibility of disposing of radioactive wastes, including spent nuclear fuel (SNF) from electrical utilities and wastes stored at federal facilities, in the unsaturated zone (UZ) at Yucca Mountain, Nevada. To be feasible, the waste isolation system must limit the release and transport of radionuclides to the accessible environment. A key concern is how water contacts a WP, which affects WP integrity and the mobilization and release of radionuclides from WPs. The ambient relative humidity in the $\mathrm{UZ}$ is high $(R H \approx 99 \%)$ and is therefore corrosive for most candidate WP materials. If $R H$ were reduced enough, WP corrosion rates would be minimal [1]. Two primary modes by which water may contact a WP are (1) condensation of water vapor that forms a liquid film on the WP and (2) liquid-phase flow. The critical factor for the first mode is $R H$ on the WP surface. For the second mode, liquid-phase contact may arise in three ways:

Drift seepage: Advective liquid-phase flow of water that enters the drift (and flows through the backfill if present) as a result of ambient percolation or decay-heat-driven condensate flow. This can include episodic nonequilibrium fracture flow or a steady seep.

Wicking: Diffusive moisture transport driven by matric potential gradients (resulting from capillary and surface forces, and osmotic effects). Because this process occurs both in the gas phase (as vapor diffusion) and the liquid phase (as imbibition), it does not require a continuous liquid phase.

Cold-trap effect: Axial vapor flow and condensation within the drift is driven by axial variations in temperature $T$ and partial pressure of water vapor $P_{\mathrm{v}}$ along the drift. Water vapor is transported from areas of higher to lower $T$ and $P_{\mathrm{v}}$ where it condenses, causing $R H$ to locally increase (up to $100 \%$ ). Large condensation rates arise in cooler areas if the following conditions are met: (1) RH is high in the adjacent rock, (2) WP heat output varies substantially from WP to WP, and (3) WPs are thermally isolated from one another.

Much of the debate over various thermal loading designs has focused on the areal mass loading (AML, expressed in metric tons of uranium per acre, MTU/acre). Of the many competing factors (e.g., operational constraints, costs, material responses) to consider in evaluating alternative thermal designs, perhaps most important is the role that decay heat plays in determining the thermalhydrological $(\mathrm{T}-\mathrm{H})$ conditions in and around the emplacement drifts and, in particular, $R H$ and liquid-phase flux on WPs. Decay heat influences the distribution of liquid saturation and liquidphase flux in the near field and altered zone, affecting radionuclide transport. Decay heat also drives coupled thermal-hydrological-geomechanical-geochemical (T-H-M-C) processes that permanently alter flow and transport properties. These effects may continue to affect radionuclide transport well after decay heat has stopped mobilizing gas- and liquid-phase flow. 
Waste packages can be arranged in the repository at Yucca Mountain in two fundamentally different ways. The first approach (the point-load design) attempts to evenly distribute the WP decay heat over the repository area by placing the WPs with roughly the same axial and lateral spacing between WPs, as is done in the advanced conceptual design (ACD) [2]. The second approach (the line-load design) lineally concentrates the WP decay heat by placing the WPs nearly end to end along the drifts. For a given AML, this maximizes the spacing between drifts and minimizes the length of emplacement drifts. We analyzed the reference AML of 83.4 MTU/acre [2] with and without engineered backfill emplaced at the time of repository closure (100 yr); however, other AMLs have also been considered [3]. Decay-heat-driven T-H behavior is markedly different for the point-load and line-load designs.

Three-dimensional calculations are required to adequately represent drift-scale $\mathrm{T}-\mathrm{H}$ behavior. Models based on the NUFT code [4] were developed to carry out such calculations [3]. A major factor to be considered in the selection of a repository design is that WP heat generation varies substantially in the WP inventory. Whereas defense high-level waste (DHLW) generates a negligible amount of heat, spent nuclear fuel (SNF) initially can generate as much as $18 \mathrm{~kW}$ per WP. The influence of WP heat output variability on $T, R H$, and liquid-phase flux experienced by WPs is markedly different for the point-load and line-load designs. A key motivation for the point-load design is to limit peak drift-wall and WP temperatures regardless of the WP sequence along the drifts. A certain degree of thermal management of the waste stream (i.e., controlling WP sequencing) may be required for line-load spacing to sufficiently limit peak temperatures.

\section{NUMERICAL MODELS AND ASSUMPTIONS}

Model calculations were conducted with the NUFT code [4], which was developed at Lawrence Livermore National Laboratory to simulate the coupled transport of water, vapor, air, and heat in fractured porous media. We included all major hydrostratigraphic units in the UZ [5] and assumed they are horizontal and of uniform thickness. The initial and boundary conditions are the same as those used in past studies $[3,6]$. We assumed a bulk permeability $k_{b}$ of 280 millidarcy, and an initial vertical liquid saturation profile based on a percolation flux of $0.3 \mathrm{~mm} / \mathrm{yr}$. However, a wide range of other conditions (including percolation fluxes ranging from 0 to $5 \mathrm{~mm} / \mathrm{yr}$ ) have also been considered $[3,6]$. The atmospheric $R H$ is assumed to be $100 \%$, so the model allows no loss of moisture by vapor diffusion to the atmosphere. Because actual (desert) $R H$ is much less than $100 \%$, the model underrepresents this loss.

The models include six major WP types (Fig. 1), resulting in a WP inventory that is representative of that assumed for the ACD [2]. The four SNF WP types are: (1) 40-yr-old 12-PWR WPs, (2) 26-yr-old 44-BWR WPs, (3) 26-yr-old 21-PWR WPs, and (4) 10-yr-old 21-PWR WPs. The two types of DHLW are Hanford site and Savannah River site DHLW WPs. The ACD assumes that $27 \%$ of the WPs contain DHLW, which is similar to the assumption made in this study that $30 \%$ of the WPs contain DHLW. The WP inventory described in Ref. 2 has an average heat output at the time of emplacement of 7.18 and $1.5 \mathrm{~kW}$ for the SNF and DHLW WPs, respectively. In our models, the SNF and DHLW averages are 7.84 and $2.4 \mathrm{~kW}$. The SNF and DHLW WPs are assumed to have lengths of 5.68 and $3.68 \mathrm{~m}$, respectively; all WPs are assumed to have a diameter of $1.8 \mathrm{~m}$. The drift diameter is assumed to be $5.5 \mathrm{~m}$, which is similar to the ACD assumption of $5 \mathrm{~m} \mathrm{[2].} \mathrm{We} \mathrm{also} \mathrm{considered} \mathrm{a} \mathrm{5-m-diameter}$ drift and found little difference in $\mathrm{T}-\mathrm{H}$ behavior between 5- and 5.5-m-diameter drifts. For thermal radiation in the drift, a WP emissivity of 0.8 is assumed; a WP emissivity of 0.3 has also been considered [3]. For the backfill cases, a granular backfill with hydrological properties similar to sand was assumed; crushed rock from the welded Topopah Spring tuff (TSw2) unit, which is where the potential repository horizon occurs, has also been considered [3]. Backfill thermal conductivities $K_{\text {th }}$ of 0.3 and $0.6 \mathrm{~W} / \mathrm{m}^{\circ} \mathrm{C}$ were considered. The invert is assumed to consist of a granular fill with the same properties as the backfill. For the line-load backfill cases, it is assumed that measures are taken to prevent backfill from filling the small gap separating WPs. For the ACD backfill cases, backfill fills the space separating WPs.

The models are applicable to areas of the repository far enough away from the edge to remain unaffected by edge-cooling effects. This allows the use of periodic no-mass/heat-flow boundaries that correspond to (1) the drift centerline, (2) the pillar centerline, (3) the plane transverse to the middle of the Hanford site DHLW WP, and (4) the plane transverse to the middle of the 10-yr-old 21-PWR WP. The ACD assumes a drift spacing of $22.5 \mathrm{~m}$ and places WPs on the basis of a constant lineal mass loading (LML) of $0.46 \mathrm{MTU} / \mathrm{m}$ along the drift (Fig. 1). For the line-load design, we assumed a 0.1-m gap between WPs, an LML of $1.11 \mathrm{MTU} / \mathrm{m}$ and a drift spacing of $53.8 \mathrm{~m}$ (Fig. 1). 


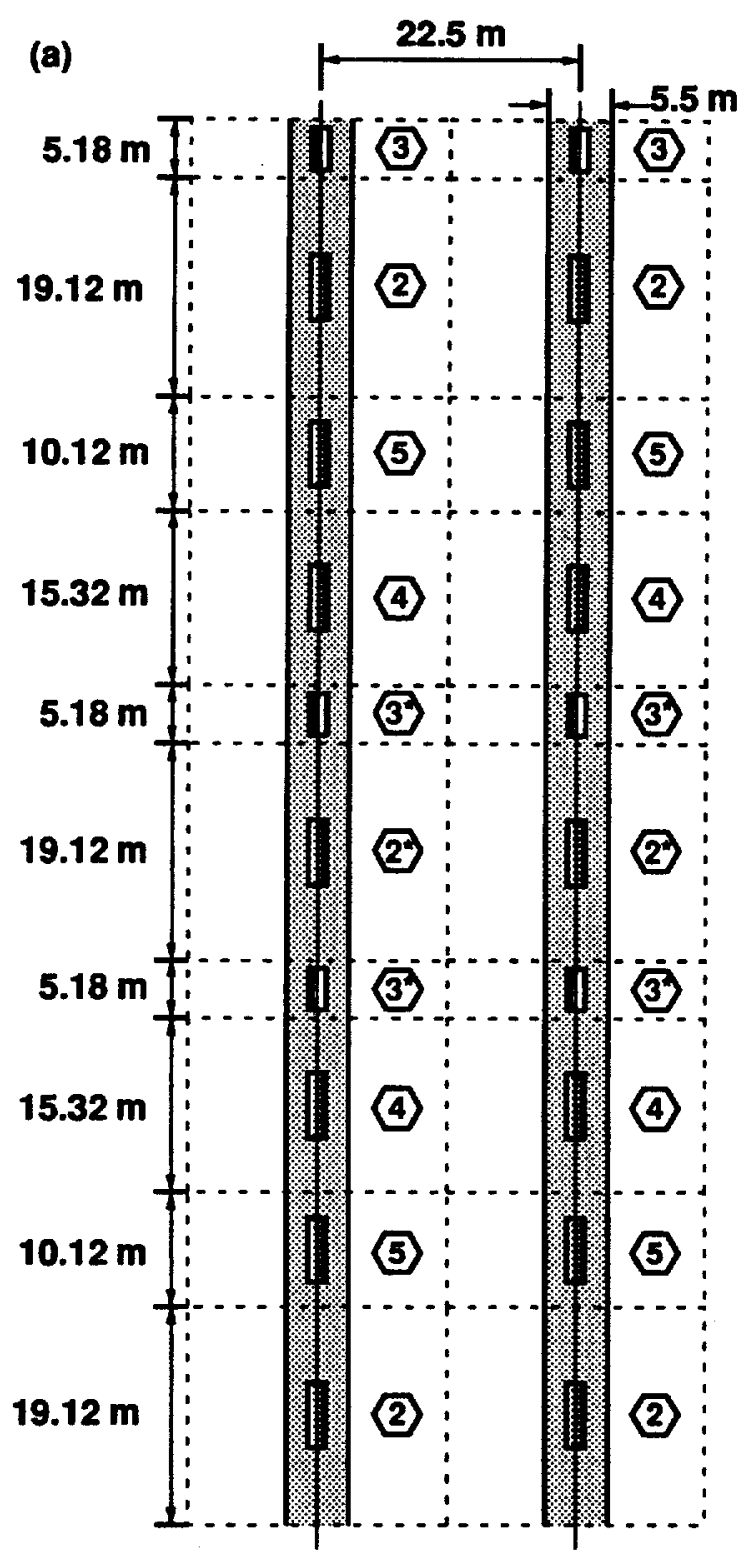

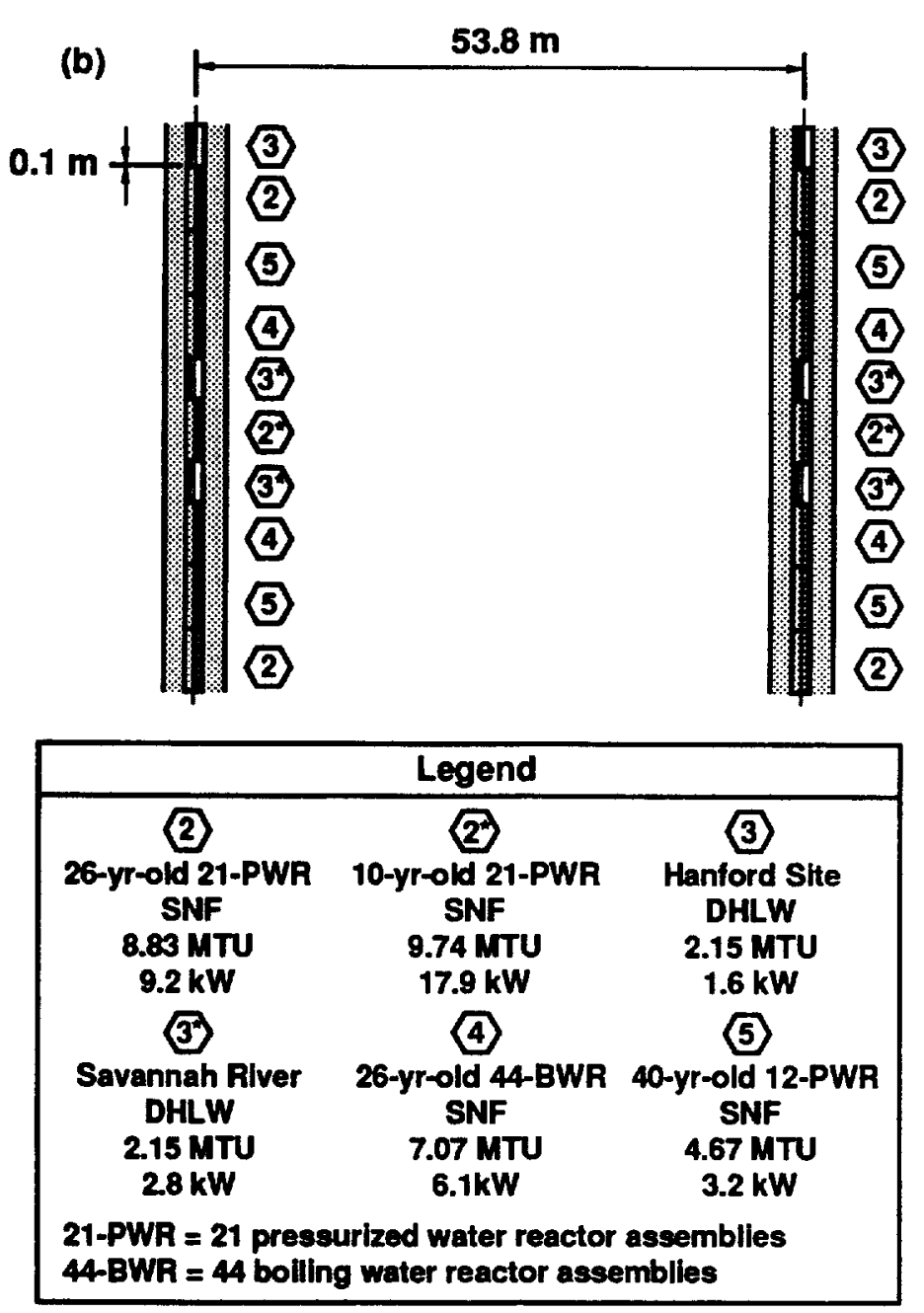

Note: heat outputs are at time of emplacement

Figure 1. Plan view of the WP layout represented in the models for (a) the ACD point-load design and (b) the lineload design. Both designs result in AML = 83.4 MTU/acre.

The respective designs have linear power loadings (LPL) of 0.5 and $1.2 \mathrm{~kW} / \mathrm{m}$. Assuming the WP inventory described in Ref. 2, a 5.335-m length for all SNF WPs (which is a more recent assumption), and a $0.1-\mathrm{m}$ gap between WPs results in an LPL of $1.13 \mathrm{~kW} / \mathrm{m}$, similar to the value used in this study.

\section{DISCUSSION OF MODEL RESULTS}

A key question is whether liquid-phase flux, arising from ambient percolation flux and decayheat-mobilized condensate flux, may enter emplacement drifts or, at the very least, prevent dryout (and $R H$ reduction) from occurring in the adjacent rock. For an 83.4-MTU/acre repository, the overall magnitude of the condensate flux depends on AML, not on LML [3]; consequently, the point-load and line-load 83.4-MTU/acre designs mobilize the same overall magnitude of condensate flux. Moreover, liquid-phase flux in the vicinity of an 83.4-MTU/acre repository is dominated by condensate flux for 2000-5000 yr [3]. Superheated conditions and a reduction in RH in the repository rock will occur if the local heat flux $q_{\mathrm{H}}$ is enough to evaporate the local incoming liquid-phase mass flux $q_{\mathrm{liq}}$ as expressed by the following relation:

$$
q_{\mathrm{H}}>q_{\mathrm{liq}} \rho_{\mathrm{liq}} h_{\mathrm{fg}},
$$

where $\rho_{\text {liq }}$ is the mass density of water and $h_{\mathrm{fg}}$ is the specific latent heat of vaporization. If $q_{\text {liq }}$ is too large, $q_{\mathrm{H}}$ is insufficient to generate superheated conditions. Near the drift, $q_{\mathrm{H}}$ is proportional to LML; further out in the rock, it is proportional to AML after the thermal fields have coalesced. Spatial 


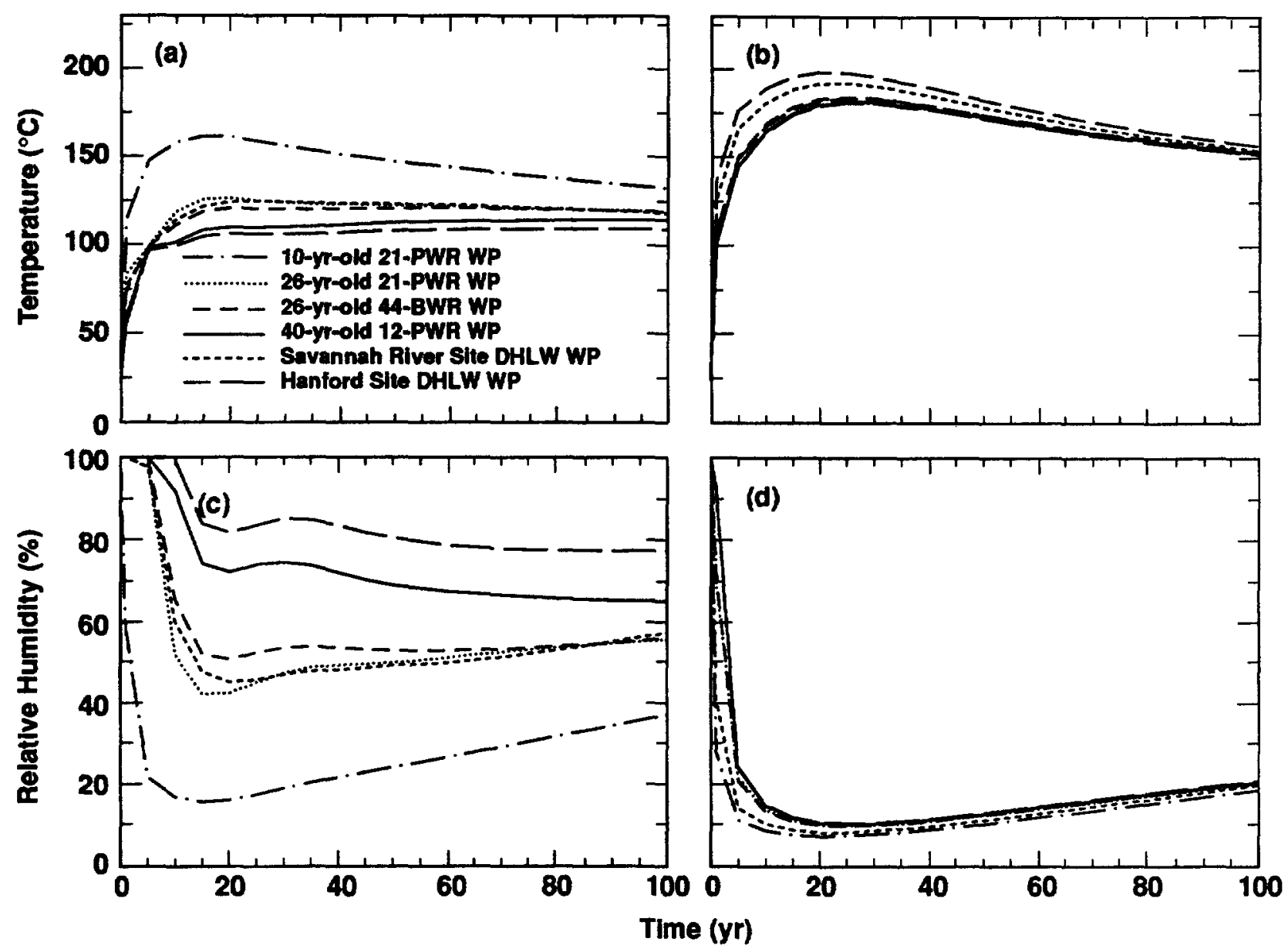

Figure 2. Temperature and relative humidity in rock at upper drift wall at various WP locations for $(a, c)$ the ACD point-load design and $(b, d)$ the line-load design.

variability in either $q_{\mathrm{H}}$ or $q_{\text {lig }}$ can result in local regions where $q_{\text {liq }}$ will prevail. Because $q_{\mathrm{H}}$ increases with proximity to the drift, it is more likely for $q_{\text {lig }}$ to prevail in the rock away from the drifts (e.g., at the pillar centerline), rather than near the drifts. Near the drifts, $q_{\mathrm{H}}$ will be 2.4 times greater (on average) for the line-load design than for the point-load design. Moreover, the $q_{\mathrm{H}}$ at the pillar centerline will be less for the line-load design than for the point-load design, increasing the likelihood that condensate will shed through the pillar of the line-load design. The point-load design results in spatial variability in both $q_{\mathrm{H}}$ and $q_{\mathrm{liq}}$ along the drift. Cooler intervals of the pointload drifts are more likely to be overwhelmed by $q_{\text {lig }}$ as a result of condensate being displaced from hotter to cooler regions and because $q_{\mathrm{H}}$ is less there; the net result is higher $R H$ and heat pipes above the cooler intervals of the point-load drift, which increase the local cooling rate and the likelihood of seepage into the drift.

The marked difference in drift-scale $\mathrm{T}-\mathrm{H}$ behavior between the point-load and line-load designs for no backfill is evident in Fig. 2. The axial WP spacing in the point-load design is large enough to thermally isolate the WPs from each other; peak drift-wall temperatures range from 107 to $158^{\circ} \mathrm{C}$, and peak WP temperatures range from 112 to $186^{\circ} \mathrm{C}$ (Table I). The close axial WP spacing in the lineload design results in efficient WP-to-WP thermal-radiative heat transfer, so that, in spite of their different heating histories, all WPs experience similar (and more beneficial) $T$ and $R H$ conditions. For the no-backfill cases, the coolest and most humid WP in the line-load design always has a lower $R H$ than the hottest and least humid WP in the ACD point-load design (Fig. 3 and Table I). The lineload design results in: (1) more locally intensive (and uniform) rock dryout around the drifts, (2) more effective condensate shedding between the drifts, and (3) less condensate buildup above the drifts.

The last two rows of Table I list the time required to rewet to $R H=65$ and $90 \%$. These $R H$ thresholds are important because corrosion studies of the candidate WP materials indicate that the critical $R H$ for significant atmospheric corrosion is $65 \%$ if a hygroscopic salt is present on the WP, or 


\begin{tabular}{|l|l|l|}
\hline \multicolumn{3}{|c|}{ No backfill } \\
\hline Repository design & ACD point load & Line load \\
\hline$T_{\text {peak }}(t<100 \mathrm{yr})$ & $112-186^{\circ} \mathrm{C}$ & $184-214^{\circ} \mathrm{C}$ \\
\hline$R H(t=100 \mathrm{yr})$ & $26-71 \%$ & $14-19 \%$ \\
\hline$R H(t=2000 \mathrm{yr})$ & $85-94 \%$ & $71-74 \%$ \\
\hline$R H(t=10,000 \mathrm{yr})$ & $93-99.9 \%$ & $94-98 \%$ \\
\hline$t(R H=65 \%)$ & $25-660 \mathrm{yr}$ & $1540-1710 \mathrm{yr}$ \\
\hline$t(R H=90 \%)$ & $1540-2390 \mathrm{yr}$ & $4260-4790 \mathrm{yr}$ \\
\hline
\end{tabular}

Table I. Temperature and relative humidity $R H$ ranges on WPs for $\mathrm{AML}=83.4 \mathrm{MTU} /$ acre. The last two rows give the time to rewet the $R H$ thresholds for the most humid and least humid WP, respectively.

\begin{tabular}{|l|l|l|}
\hline \multicolumn{3}{|c|}{ Backfill $\left(K_{\mathrm{th}}=0.6 \mathrm{~W} / \mathrm{m}{ }^{\circ} \mathrm{C}\right)$} \\
\hline Repository design & ACD point load & Line load \\
\hline$T_{\text {peak }}(t>100 \mathrm{yr})$ & $119-344^{\circ} \mathrm{C}$ & $245-268^{\circ} \mathrm{C}$ \\
\hline$R H(t=120 \mathrm{yr})$ & $1-55 \%$ & $2-3 \%$ \\
\hline$R H(t=2000 \mathrm{yr})$ & $43-96 \%$ & $48-52 \%$ \\
\hline$R H(t=10,000 \mathrm{yr})$ & $62-99.7 \%$ & $72-80 \%$ \\
\hline$t(R H=65 \%)$ & $170-12,250 \mathrm{yr}$ & $3550-4770 \mathrm{yr}$ \\
\hline$t(R H=90 \%)$ & $1340-58,960 \mathrm{yr}$ & $26,200-41,030 \mathrm{yr}$ \\
\hline
\end{tabular}

\begin{tabular}{|l|l|}
\hline \multicolumn{2}{|l|}{ Backfill $\left(K_{\text {th }}=0.3 \mathrm{~W} / \mathrm{m}{ }^{\circ} \mathrm{C}\right)$} \\
\hline ACD point load & Line load \\
\hline $132-537^{\circ} \mathrm{C}$ & $344-362^{\circ} \mathrm{C}$ \\
\hline $0.5-38 \%$ & $1-1 \%$ \\
\hline $24-95 \%$ & $34-38 \%$ \\
\hline $41-99.6 \%$ & $57-64 \%$ \\
\hline $200-27,820 \mathrm{yr}$ & $10,600-15,960 \mathrm{yr}$ \\
\hline $1440-104,880 \mathrm{yr}$ & $53,330-71,610 \mathrm{yr}$ \\
\hline
\end{tabular}

$90 \%$ if the WP surface is free of salt [7]. Whether liquid water can enter the drift and reach (and evaporate on) a WP, leaving a salt buildup, is of critical importance to WP integrity. For the nobackfill cases, the line-load design significantly extends the time required to reach these $R H$ thresholds (relative to the point-load design). When a low- $K_{\text {th }}$ backfill (that limits wicking) is used, the time to reach these $R H$ thresholds is further increased for all WPs in the line-load design, while for the point-load design, it is only increased for the SNF WPs (Fig. 4); consequently, DHLW WPs do not experience the benefit of $R H$ reduction in the point-load design. Low- $K_{\text {th }}\left(\right.$ e.g., $0.6 \mathrm{~W} / \mathrm{m}^{\circ} \mathrm{C}$ ) backfill accentuates thermal isolation in the point-load design, causing large variability in peak WP temperatures $\left(119-344^{\circ} \mathrm{C}\right.$ ), while for the line-load design, peak WP temperatures only range from 245 to $268^{\circ} \mathrm{C}$. For the backfill cases, the line-load design substantially decreases the maximum peak WP temperatures (relative to the point-load design).

The additional $R H$ reduction for the backfill cases arises from the large temperature difference $\left(\Delta T_{\text {drift }}\right)$ between the WP and drift wall [6]. This effect (called the "drift- $\Delta R H$ effect") occurs in addition to $R H$ reduction resulting from rock dryout. Assuming uniform $P_{\mathrm{v}}$ in the drift, $R H$ on the WP is given by

$$
R H_{\mathrm{wp}}=R H_{\mathrm{dw}} \frac{P_{\mathrm{sat}}\left(T_{\mathrm{dw}}\right)}{P_{\mathrm{sat}}\left(T_{\mathrm{wp}}\right)},
$$

where $R H_{\mathrm{dw}}$ is $R H$ at the drift wall, $T_{\mathrm{dw}}$ and $T_{\mathrm{wp}}$ are the drift-wall and WP temperatures. For decreasing backfill $K_{\text {th }} \Delta T_{\text {drift }}$ increases, resulting in a larger and more persistent reduction in $R H$. The influence of thermal design on WP integrity is pronounced. For example, the time to reach $R H=65 \%$ is only $25-660$ yr for the ACD no-backfill case, while it is $10,600-15,960 \mathrm{yr}$ for the lineload backfill case with $K_{\text {th }}=0.3 \mathrm{~W} / \mathrm{m}^{\circ} \mathrm{C}$ (Table $\mathrm{I}$ ). The time to reach $R H=90 \%$ is only $1540-2390 \mathrm{yr}$ for the ACD no-backfill case, while it is $53,330-71,610 \mathrm{yr}$ for the line-load backfill case. 

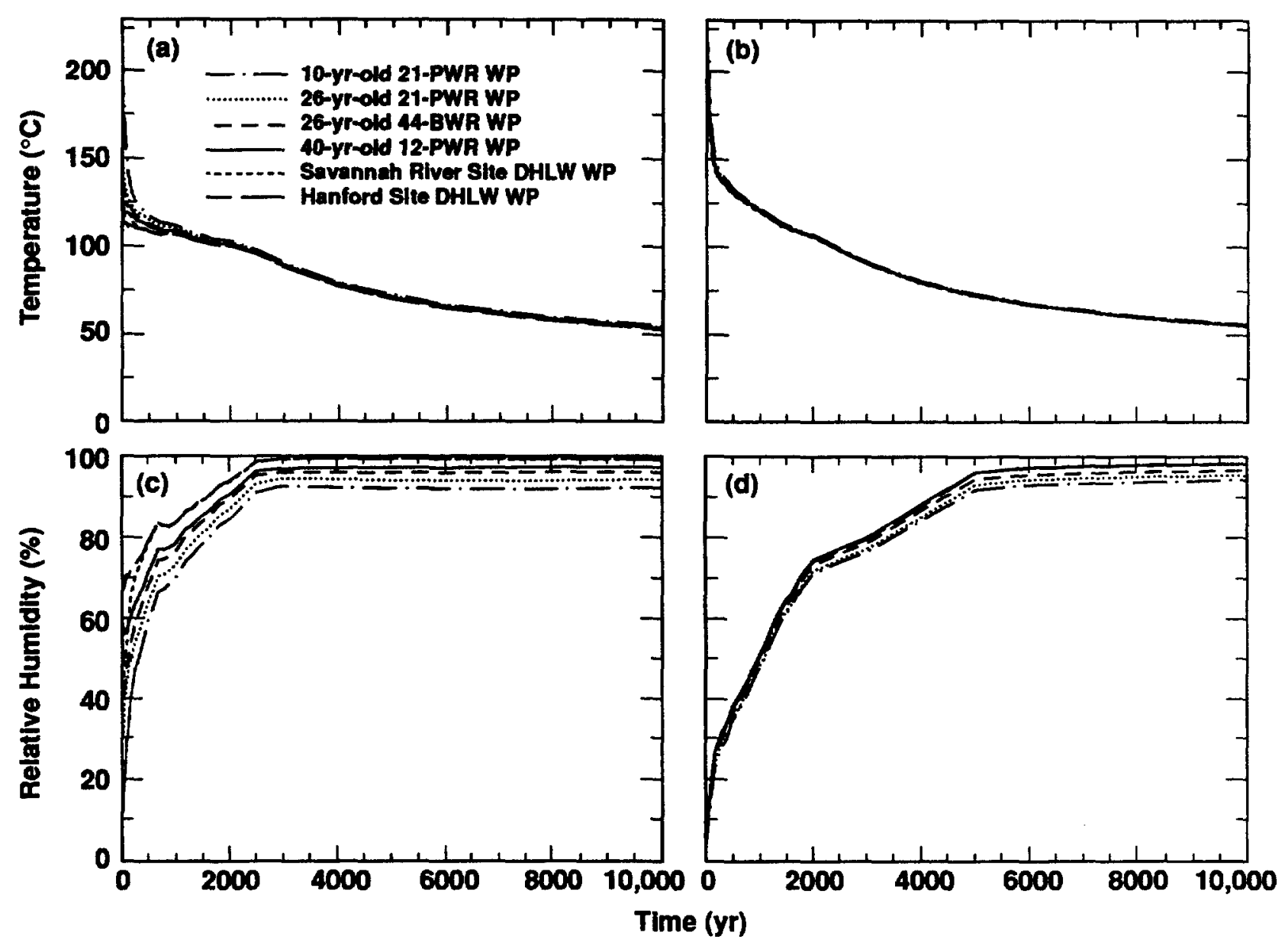

Figure 3. Temperature and relative humidity on upper WP surface for no backfill. Curves are plotted for $(a, c)$ the ACD point-load design and $(b, d)$ the line-load design.

The possibility of hydrothermal alteration of the vitric nonwelded Paintbrush tuff (PTn) unit that overlies the repository is an important issue. If it occurs, it could significantly reduce the ability of the PTn to imbibe (and thereby attenuate) fast fracture flow. These changes may also increase the percolation flux at the repository. The 83.4-MTU/acre point-load and line-load designs drive markedly different changes in $T$ and liquid saturation $S_{\mathrm{lig}}$ in the PTn, which are the result of how effectively condensate sheds between the drifts. More efficient condensate shedding between the line-load drifts results in less condensate buildup above the repository than the point-load design. The vertical extent of the upper heat-pipe zone depends on the amount of condensate available (above the repository) to reflux. For the point-load design, the maximum vertical extent of the upper heat-pipe zone is $100 \mathrm{~m}$ closer to the ground surface than in the line-load design (Fig. 5a). Figure $5 \mathrm{~b}$ shows how the larger condensate buildup above the ACD repository inundates the matrix (raising $S_{\text {liq }}$ to $99 \%$ ) in the PTn and causes the peak temperature rise in the PTn to be $30^{\circ} \mathrm{C}$ higher than in the line-load design. The condensate buildup above the ACD repository causes $S_{\text {liq }}$ in the PTn to be greater than ambient for thousands of years. The $S_{\text {liq }}$ increase, together with the temperature rise, may be enough to cause hydrothermal alteration that reduces the ability of the PTn to imbibe fast fracture flow. The upper extent of the condensate zone overlying the line-load repository remains well below the PTn; consequently, $S_{\text {liq }}$ in the PTn never exceeds ambient. Greater condensate buildup above the $A C D$ point-load repository also causes the peak temperature rise near the ground surface to be almost twice that for the line-load design.

\section{CONCLUSIONS}

A three-dimensional model representing a realistic mixture of WPs was used to compare T-H behavior for two different approaches to arranging the WPs in a potential repository at Yucca Mountain. The point-load approach used in the ACD places WPs equidistant from each other to 

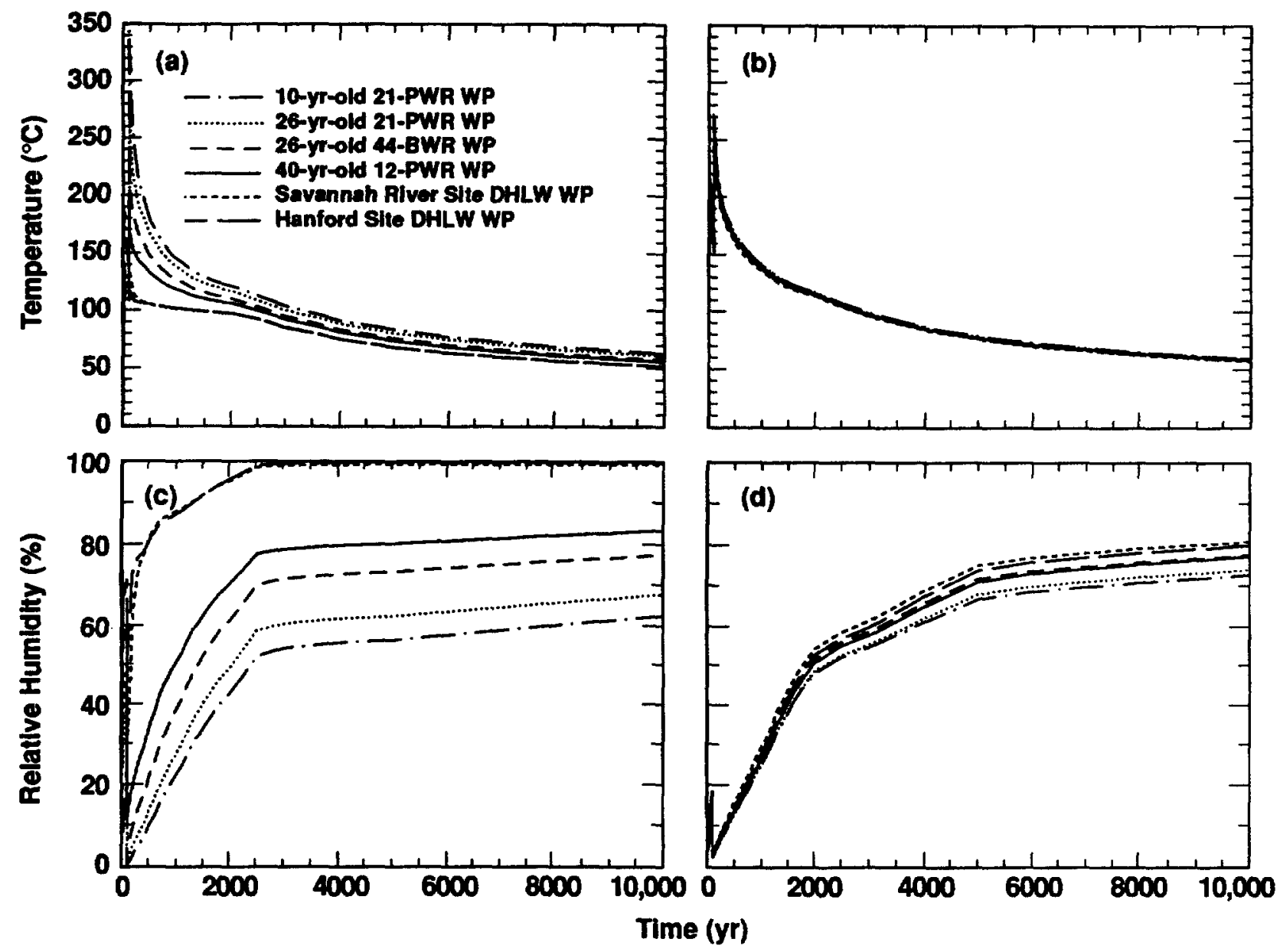

Figure 4. Temperature and relative humidity on upper WP surface for backfill emplaced at $100 \mathrm{yr}$ with $K_{t h}=0.6 \mathrm{~W} / \mathrm{m}^{\circ} \mathrm{C}$. Curves are plotted for $(\mathrm{a}, \mathrm{c})$ the $\mathrm{ACD}$ point-load design and $(\mathrm{b}, \mathrm{d})$ the line-load design.

spread the WP decay heat, thereby limiting peak drift-wall and WP temperatures. The line-load approach lineally concentrates the WP decay heat by placing WPs nearly end to end in widely spaced drifts. A key consideration in evaluating alternative WP layouts is the markedly different T-H behavior that occurs in and around drifts, including: (1) how condensate returns to the repository, (2) how much heat is available near the drifts to vaporize incoming liquid water, and (3) the spatial variability in heat flux and condensate flux along the drifts. The line-load design causes the pillar to be a more preferential pathway for condensate drainage than the point-load design. Moreover, the line-load design has 2.4 times the local heat flux near the drifts (on average) to vaporize incoming liquid water than the point-load design. Consequently, it is more difficult for condensate to drain into line-load drifts than point-load drifts; the coolest and most humid WP in the line-load design is always less humid than the hottest and least humid WP in the point-load design. The point-load design thermally isolates WPs from each other, causing large variability in $T$, $R H$, and condensate flux along the drifts. The close axial WP spacing in the line-load design allows efficient WP-to-WP heat transfer that homogenizes the heat flux distribution along the drift. When a low- $K_{\text {th }}$ backfill is used, this heat-flux homogenization greatly limits peak WP temperatures compared to the point-load design. A larger and more persistent reduction in $R H$ on WPs occurs when the drifts are backfilled with a low- $K_{\text {th }}$ granular material that limits wicking.

The line-load design provides the following advantages (compared to the ACD): (1) reduction (up to $60 \%$ ) in the required length (and number) of emplacement drifts with a corresponding cost reduction, (2) large reduction in backfill volume, (3) narrower range of $T$ and $R H$ for which natural and engineered materials must be tested, (4) less spatially variable drift-scale T-H behavior to be accounted for in performance analyses, (5) all WPs (including DHLW) experience the benefit of $R H$ reduction, (6) decreased probability of condensate flow entering the drifts, (7) decreased tendency for decay-heat-driven temperature and liquid saturation increase (and any resulting hydrothermal alteration) in the PTn unit, 

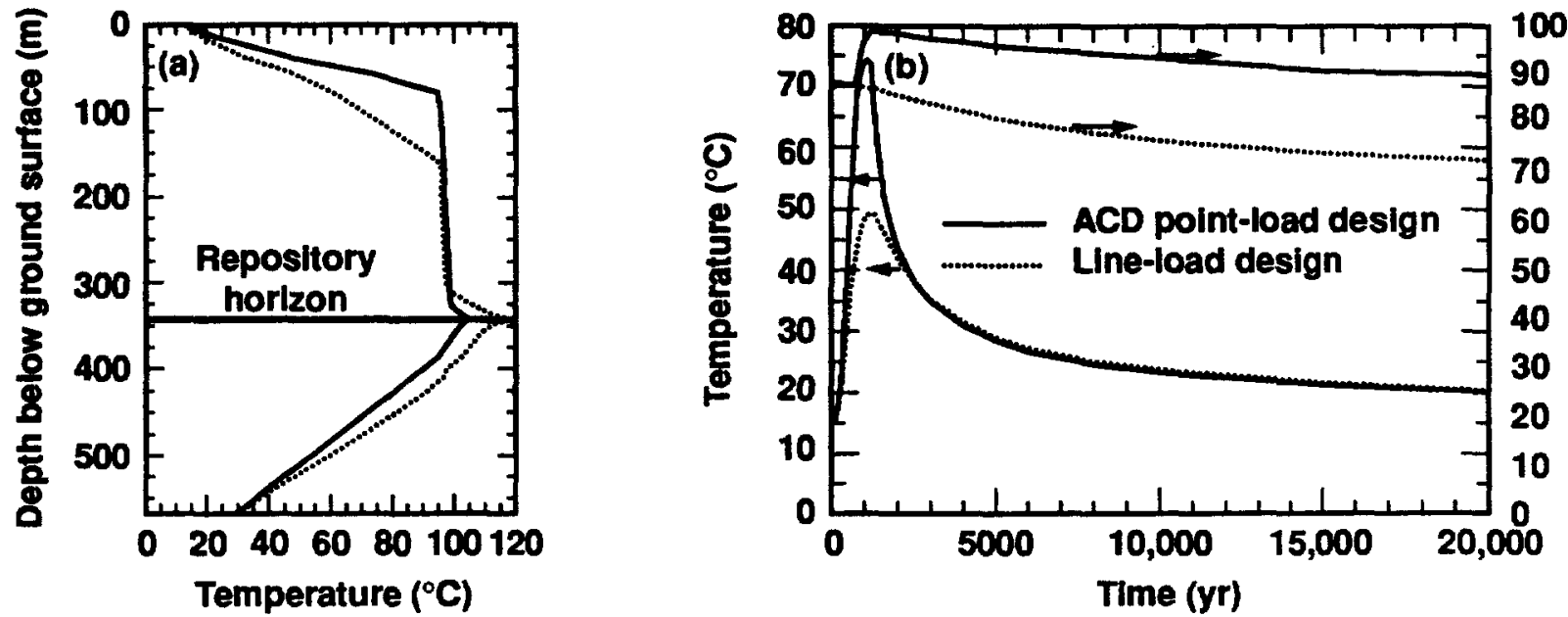

들

Figure 5. Vertical temperature profile (a) at $1000 \mathrm{yr}$ along a line intersecting the Hanford site DHLW WP for the $A C D$ point-load design and the line-load design. Also plotted (b) are liquid saturation and temperature histories in the PTn unit $295 \mathrm{~m}$ above the repository horizon.

and (8) a reduction in peak temperature rise near the ground surface. The cost associated with any WP sequencing that may be necessary to implement the line-load design is worthwhile given the important benefits of this approach.

\section{ACKNOWLEDGMENTS}

We acknowledge the review of Jim Blink, the editorial assistance of Robert Kirvel, and the graphical support of Rick Wooten and Dan Fletcher. This work was performed under the auspices of the U.S. Department of Energy by the Lawrence Livermore National Laboratory under contract W-7405-ENG-48 and was supported specifically by the Yucca Mountain Site Characterization Project at LLNL.

\section{REFERENCES}

1. Stahl, D., J.K. McCoy, and R.D. McCright, "Impact of Thermal Loading on Waste Package Material Performance," Proceedings Material Research Society XVIII Symposium on the Scientific Basis for Nuclear Waste Management, Material Research Society, Pittsburgh, PA, Oct. 23-27 (1994).

2. CRWMS Management and Operating Contractor, "Mined Geologic Disposal System Advanced Conceptual Design Report," Vol. 2, B00000000-01717-5705-00027, Rev. 00 (1996).

3. Buscheck, T.A. in Wilder, D.G. (editor), Near-Field and Altered-Zone Environment Report, Volume II, Chapter 1: "Hydrothermal Modeling," UCRL-JC-124998, Lawrence Livermore National Laboratory, Livermore, CA (1996).

4. Nitao, J.J., "The NUFT Code for Modeling Nonisothermal, Multiphase, Multicomponent Flow and Transport in Porous Media," EOS, American Geophysical Union, Vol. 74, no. 3, pg. 3 (1992).

5. Peters, R.R., E.A. Klavetter, I.J. Hall, S.C. Blair, P.R. Hellers, and G.W. Gee, Fracture and Matrix Hydrologic Characteristics of Tuffaceous Materials from Yucca Mountain, Nye County, Nevada, SAND841471, Sandia National Laboratories, Albuquerque, NM (1984).

6. Buscheck, T.A., J.J. Nitao, and L.D. Ramspott "Localized Dryout: An Approach for Managing the Thermal-Hydrological Effects of Decay Heat at Yucca Mountain," Proceedings Materials Research Society XIX International Symposium on the Scientific Basis for Nuclear Waste Management, Materials Research Society, Pittsburgh, PA, Nov. 27-Dec. 1, 1995. Also UCRL-JC-121232, Lawrence Livermore National Laboratory, Livermore, CA (1995).

7. Jones, D.A., Principles and Prevention of Corrosion (Macmillan Publishing Company, New York, (1992). 


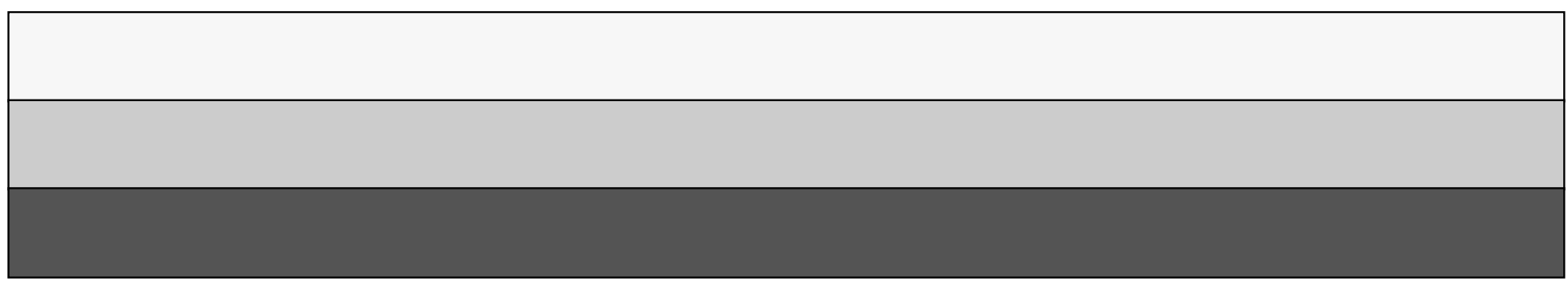

